\title{
Caring for seals and the Wadden Sea: Multispecies entanglements in seal rehabilitation
}

\author{
Doortje Hörst ${ }^{1}$ (1)
}

Received: 28 September 2020 / Accepted: 15 July 2021 / Published online: 17 September 2021

(c) The Author(s) 2021

\begin{abstract}
The Wadden Sea is a busy environment in which multiple species share a limited space. Humans use the area for recreation and economic purposes, while it also represents an ecologically valuable space as one of the largest intertidal areas in the world. Sharing the Wadden Sea with multiple species is recognized as a challenge by a seal rehabilitation center in the Netherlands, who cares for seals and their habitat, the Wadden Sea. To diminish harmful effects of human-seal interactions, the seal rehabilitation center educates their visitors to care for the Wadden Sea through at least three different educational practices (seal releases, beach cleanups, and through an exhibition at the visitor center). By taking a relational perspective to analyze these educational moments, it becomes apparent that different "natures" are brought into being. That is, by creating different experiences in multiple circumstances, relations between what is experienced or enacted as being part of the Wadden Sea environment changes. An important focus in this article is the diverse positions humans take up in relation to the Wadden Sea as they are encouraged to care for it and the seals. Instead of taking a human and nature distinction as a starting point, I will show that these educational practices produce fluid and dynamic relations between "humans" and "nature," enabling multiple engagements with the sea and those who inhabit it.
\end{abstract}

Keywords Nature $\cdot$ Wadden Sea $\cdot$ Care $\cdot$ Conservation $\cdot$ Natureculture

\section{Contesting "nature" at the Wadden Sea}

At the World Natural Heritage designated Wadden Sea, "nature" has been a complex and contested concept, especially regarding the positions of humans and their influences in this environment. Since the settling of humans in the Wadden area as far back as $600 \mathrm{BC}$, humans, the sea, and its sediments have interacted with and changed this environment (Bazelmans et al. 2012). Since the establishment of the Wadden Sea Area as a trilateral natural protection site, human activities in the area are acknowledged and included in environmental protection policies (Enermark 2005: 1005). For example, the international Wadden Sea Forum adheres to the Integrated Coastal Management Zone (ICZM) approach (Wadden Sea Forum 2013). The ICZM approach stimulates integration by focusing on the involvement of many different stakeholdersecologic, social, and economic-and of organizations

Doortje Hörst

D.hoerst@uq.net.au

1 School of Human Movement and Nutrition Sciences, University of Queensland, QLD, Brisbane, Australia functioning on different political scales. The Agenda voor het Waddengebied 2050 (Ministerie van Infrastructuur en Waterstaat 2020) also clearly states to have both ecological and social goals at the Dutch Wadden Sea. It is acknowledged that an integrative approach could lead to dialogue and potential for responsible human use in the area (Waddenforum 2013; Egberts 2019: 69). However, oftentimes conflict arises because "nature" is still treated as a separate entity from "human," "social," or "cultural." This issue is particularly present in critiques on heritage management. For example, to apply for the UNESCO World Heritage designation, "pure" natural qualities were emphasized, ignoring the Wadden Sea landscape's political, social, and cultural dimensions (Krauss 2005: 46). After acquiring the official World Heritage designation in 2009, this opposition was strengthened because it became formally grounded in legislation and administration (Walsh 2018; Egberts 2019). Historically, boundaries between nature and culture seem to have hardened, because national policies have focused predominantly on the ecological protection of the seaside, while it conceived cultural heritage situated on the land behind the dykes as of 'minor importance' (Egberts 2019: 67). 
Making a distinction between nature and culture also happens with more nuance when acknowledging human influences in the Wadden Sea. Hans-Ulrich Rösner, the director of the WWF Wadden Sea division in Germany (2019: 82), argues that "[anthropogenic forces] do not have the extent or impact to make the Wadden Sea a cultural landscape." He contrasts the concept of a "cultural landscape" with that of a "natural landscape," which he defines as "a landscape that is predominantly formed by natural forces, the latter covering the whole range of geological to biological processes" (ibid: 85). In this approach, it seems to depend on the influence humans have on "nature" equating the idea that more human influence (potentially) means less nature. While this is a gradual scale, from this perspective nature and culture remain opposites, preventing a dialogue that might lead to an integrative approach that is so much needed in an ecologically valuable area with increasing human influence (Kabat et al. 2012: 13).

As a call for an integrative approach to "nature" is growing in the Wadden Sea Area while the opposition between nature and culture still seems strong, it is relevant to take a close look at how nature conservation is actually practiced. The tendency of nature conservation organizations to draw on a nature/culture dichotomy is quite entrenched if not constitutive for nature protection (De Koning and Steins 2019; Walsh 2020). Nature conservationists focusing on the Wadden Sea in the Netherlands, for example, perceive "nature" as ideally self-sustaining, non-human, while humans are conceived to enhance "nature" in such a way that this behavior contributes to maintain that ideal conception (De Koning and Steins 2019: 54-55). The purpose of this article is to show that nature/culture boundaries are much messier in practice.

By focusing on practices, it becomes possible to "doubt" if this nature/culture distinction also holds up during events where humans and non-humans enact multiple "natures" in a particular situation (Mol 2002: 48). That is, what kind of "nature" appears when multiple actors, humans, nonhumans, or objects relate to each other in specific ways? What position do "humans" have in those relations as they emerge? This approach is not about an exploration of different perspectives, in which the material object possesses a stable reality or status (Mol 2002: 12). Rather, the material object's reality depends on the dynamic relations formed that enact the object in a certain way: the assemblage of relations brings the object into being, and it emerges from interaction (Deleuze and Guattari 1987). Hence, "nature" is not an essentialized object out there but a relational entity. "Nature" during one event is not "nature" in another. They are different, though partially related (Strathern 1991).

To account for multiple actors, human, non-human, or object and to take seriously their influences on the assemblage, this research draws on multispecies or more-than-human research (Potter and Hawkins 2009; Kirksey and Helmreich 2010; Danby et al. 2019). To emphasize the relationality of "culture" to "nature," Donna Haraway (2003) proposes to use the neologism "natureculture." This concept maintains such a far-reaching integration of "human" and "nature" that it becomes impossible to speak about them as separate entities and recognizes humans as always part of "nature." Multispecies research has widened the scope to include not only organisms, but also microbes, and "abiotics," such as landscape features or pollution (Helmreich 2009; Van Dooren et al. 2016: 4; Evers 2019).

The concept natureculture is analytically useful for the purposes of this article as it stimulates a dynamic approach and challenges any binary separation. Still, it will exist paradoxically next to the word "nature." "Nature" is the word interlocutors used when speaking about the Wadden Sea area. By staying close to their wording and combining it with natureculture analytically, it becomes possible to see how "nature" is dynamic, also in the experience of participants at a nature protection organization at the Dutch Wadden Sea, who tend to differentiate between "nature" and "culture." Thus, 'nature', as approached in this article, is a relational assemblage of matter and organisms (Deleuze and Guattari 1987; Barad 2007). All events discussed in this article pertain to and enact the Wadden Sea in different ways. This opens up opportunities to discuss how "humans" relate to other matter and species relevant for the assemblage of the Wadden Sea and whether "humans" (which humans?) are considered as a part of that assemblage at all.

The nature conservation organization studied in this paper is a seal rehabilitation center at the Dutch Wadden Sea coast. The seal rehabilitation center (from now on, seal center) takes care of wounded, sick or orphaned seals and releases them back into the sea once they have recovered. From an ecological perspective, the seal population is currently doing well, and consequently the protective focus of the seal center recently shifted towards care for the seals' habitat. This encounter with and intervention in the lives of seals forces members of the seal center to reflect on their relationship with "nature." Through education, the seal center aims to inspire people to behave differently, more responsibly and caringly, not only in relation to the seals but also with regard to the Wadden Sea as an environment. Here, different educational practices employed by the seal center emerge that constantly reshape the boundaries of "nature." Taking this aspect as a starting point, this paper will elaborate on the dynamic processes in which humans take different positions in various assemblages that encourage care for seals and their habitat. This leads me to a research question that focuses on these dynamics: what natureculture relations emerge between humans and the Wadden Sea through practices of education, with which the seal center intends to encourage people to care for the surrounding Wadden Sea? 
This research question requires a detailed approach that is based on and allows for spontaneous events: participant observation. This method requires the researcher to be intimately involved with events, human and non-human practices on site. For my data collection, I collected detailed fieldnotes about my observations of events, conversations, and also of my own behavior and responses to the field. This approach required me to establish a practice of reflexivity, in which I critically engaged with my observations and experiences in order to use them to better understand the relationships between humans, seals and the Wadden Sea.

Four months of participant observation led me to attend three different educational events at various times. During these occasions, the seal center aimed to "focus on personal, intimate experiences that leave behind a deep and lasting impact, not through a virtual medium, but through lived experience," as they write in their annual report (Stichting Zeehondencentrum Pieterburen 2018: 15). One of these educational events was the "boat release." During this event, recovered seals which have stayed in the center are released back into "nature" from a sandbank, accompanied by staff and visitors. The second event that will be discussed here is the exhibition room at the visitor center, where the Wadden Sea is enacted through various objects, micro-plastics, and seals. The third educational event is a beach cleanup, organized monthly by the seal center and open for anyone who wants to join. Analyzing these three events, we will see that "nature" and particularly the boundary between nature and culture is fluid. What nature entails and how it is enacted depends on the event. While the Wadden Sea is enacted as "pristine nature" quite clearly during a boat release, literally excluding humans from the picture, the beach cleanup as a practice makes human participants a central part of "nature" indicating that those divisions are dynamic. It is in the spontaneous, unpredictable moments that opportunities and openings might arise of how we might want to more structurally engage with the Wadden Sea as a valuable ecological and social area.

\section{A relational Wadden Sea environment}

The nature-culture divide has been problematized more widely than at the Wadden Sea. William Cronon (1996) described within the context of the settlers of the USA how "wilderness" is a socially constructed concept that is based on a nature/culture dichotomy. Instead of acknowledging the historically continued use of the land, the sense of "wilderness" led to the creation of protected national parks and the evacuation of those people who lived on that land. It was an erasure of "culture" that historically interacted with the land that made it possible to create a "pristine nature" for elites to enjoy it leisurely (ibid.: 16). If this is to be extended to the Wadden Sea, we could say that the separation between nature and culture is only made possible as "culture" is socially erased from "nature," which is exactly what heritage specialists argue (Krauss 2005; Egberts 2019). Bruno Latour (1993) analyzes how nature/culture separations characterize the "Moderns." The "Moderns" is a philosophical concept to signify those who try to purify nature from culture and vice versa, to hold up their distinction. At the same time, natureculture hybrids are found everywhere, even in such a multitude that a rejection of hybrids to favor purification has become impossible. Latour argues that we can find relations between hybrids and their acts of purification in practices and networks, leaving behind the antithesis of a distinction between nature and culture that Modernity has constituted (ibid.: 48). In a similar vein, Alexis Shotwell (2016) finds examples of the rhetoric of purity and impurity—or hybrids in Latour's terms-in everyday life, as well as within organizations, including those focusing on nature protection. For Shotwell, rhetoric of purity and impurity often coexist. To take up these aspects and figure out how diverse positions of humans in relation to "nature" are enacted, I will focus on relations established during practices to see how the work of purification or hybridization gets constituted during the messiness of events.

A practice approach presumes a noncoherent world through the tactic of "not knowing" (Law 2004). The researcher does not assume to know what 'nature' is. Rather, she explores what 'nature' might be, depending on the relations that enact 'nature' in certain circumstances (Yates-Doerr and Mol 2012). To take one example of a practice study, Jeannette Pols (2006) discusses how citizenship is practiced when washing patients at the mental healthcare home. She recognizes four repertoires of citizenship, of which three encourage a patient's autonomy, and the fourth stimulates relationality (Pols 2006: 98). Even though the analytical starting point is relational, the outcome might be that something — but not solely—opposite is produced. It opens up possibilities to see how multiple practices also lead to multiple outcomes with different effects or rhetoric. Because of this dynamic aspect, it opens up to see how something particular is multiple, depending on how something is enacted or practiced.

Who then is implicated in those noncoherent "becomings" that emerge from practices, and who constitutes those relations? The complexity of such "becomings" is also evident in multispecies relations (Haraway 2003; Sundberg 2013; Van Dooren et al. 2016). Not only are non-humans inherently part of human life-as, for example, bacteria are an essential part of the human gut tissue (Haraway 2008: 220) - they are also potentially meaningful actors who both enact and are enacted, changing the (political) environment (Law and Mol 2008). Such insights have emerged from diverse backgrounds, including from indigenous scholars and knowledge holders. For example, in Australia, kin 
relations with non-human inhabitants of outer space deeply problematize ongoing activities of space colonization, while Matsutake mushrooms create openings to the niches of (anti) capitalism, farm cows challenge Hindu nationalism, and chimps lay bare colonial relations in nature conservation in Malaysia (resp. Mitchell et al. 2020; Tsing 2015; Govindrajan 2018; Parreñas 2018). By decentering humans, the analysis opens up to include how other-than-humans who are part of the relatedness influence the emergence of 'nature' in its varied forms, also during educational practices of the seal center.

During the educational practices of the seal center, I found it is not only more-than-human critters that influence the experience of the environment. The sea and the sandbanks of the Wadden Sea often evoke emotions and leave lasting impressions (Sijtsma et al. 2012). Moreover, this is specifically what the seal center wants to evoke in their visitors during an educational event. In new materialist pedagogical literature, a concept that entails this emotional educative experience with the environment is "place-responsiveness" (Payne and Wattchow 2009a, b; Bonnett 2013; Mannion et al. 2013; Hill and Brown 2014). This means that as people learn about a place, they may come to care about it as they have multiple embodied experiences with local wildlife or landscapes (Hill and Brown 2014: 227; Brown 2019). By acknowledging the potential of place-responsiveness through a relational lens, I take into account the influence of spatial surroundings such as the sea and the sandbanks. This is especially important as volunteers or employees of the seal center did not often explicitly educate their visitors. It was left to the objects, landscape and seals to 'speak for themselves', while to some extent being carefully arranged by human actors.

A word that resonates with my approach and case study is the word 'togetherness', coined by Sebastiaan Abrahamsson and Filipo Bertoni (2014). As they study vermicomposting with worms, they study what happens in the bucket with multiple layers, with worms, waste/ food, earth and humans. Worms, humans and food need to somehow work through their differences to create a situation that satisfies all. If humans dispose of the wrong kind of food in the vermicomposting bin, worms might leave or die (ibid.: 134). Building on trial and error, the togetherness only works when it profits from a relationship of care. Here, I will follow Maria Puig dela Bellacasa (2010) in using Joan Tronto's (1993) definition of care: "Everything that we do to maintain, continue and repair 'our world'. So that we can live in it as well as possible. That world includes our bodies, ourselves and our environment, all that we seek to interweave in a complex, life sustaining web" (Tronto 1993, 103 as cited in Puig dela Bellacasa 2010: 164). This definition allows for a multiplicity of caring actors, human and non-human, and an open-ended multiplicity of practices that involve care.
The seal center aims to encourage diverse practices of care to create a working 'togetherness' for humans, seals and the Wadden Sea ecology in general, as I will show in more detail later. While the vermicomposting bin presupposes a togetherness with recurring main characters, the Wadden Sea leaves us with many possible relations and actors. Moreover, I will extend the relations of togetherness to humans and nonhumans that come to matter in less tangible ways, for example, those that come to matter through memory. What becomes a "togetherness" is dynamic and diverse, depending on how more than human participants relate during a certain practice. During such a temporary togetherness established by natureculture relations, "nature" emerges in multiple ways that may or may not encourage a working togetherness through care relationships.

\section{Caring for seals at the seal center}

From September 2018 to January 2019, the seal center welcomed me as a researcher and volunteer to help care for the seals and join the educational projects. With a focus on human and more-than-human relations, my approach was to allow the research site to lead me to what was important, writing fieldnotes to keep track of my experiences. Quickly, I learned the important role the seal center attributes to education. The three main reasons for seals to end up in rehabilitation is because they are found sick with parasites, entangled in waste or nets, or lost due to disturbances that cause seal pups to lose their mother. ${ }^{1}$ These disturbances may include storms but also occur due to human action. The seal center provides educational events to encourage people to care and behave responsibly to reduce the need for seal rehabilitation, at least for those seals who are in rehabilitation due to human-induced harm.

To get familiar with the way the seal center educates people about the Wadden Sea, I spent one day per week in the months of October to December in the visitor center. Here, visitors are able to watch seals in different stages of the rehabilitation process, a process in which a seal normally stays two to three months under professional care in the seal center (depending on how fast they recover). As a participant observer, I joined the guides of the visitor center who either talked informally and privately to visitors and at other times held presentations in front of groups. I checked my findings regularly with those guides. Being here every week, I grew familiar with the objects and information on display in the visitor center and the (often similar) questions visitors raised

\footnotetext{
${ }^{1}$ Rehabilitating seals who are ill because of 'lungworms' is a specific Dutch policy, one that is and has been trilaterally and nationally under much discussion (see Hörst 2019).
} 
in response to these objects as well as to the seals in rehabilitation. Based on these experiences and conversations, I focus my analysis of the visitor center on the displays that encouraged most of the interaction between visitors and guides.

On the special occasion of the seal release, visitors get to sail to a sandbank in the middle of the eastern Dutch Wadden Sea. Seals are brought on board in wooden boxes and are released on the sandbank. The boat release was an experience that was difficult to translate to notes. There was something special about being there in relation to the landscape and seals. Normally, a volunteer gets only one opportunity to join a boat release. Near the end of the fieldwork, however, I befriended the skipper of the boat and went to several more boat releases to complement, check, and refine my first findings. With all occasions, the sense of the experience being special was central and featured between the lines in my descriptions. I chose an event in November that was most exemplary and explicit to analyze natureculture dynamics during these encounters.

The beach cleanup did not seem to be a very treasured educational initiative of the seal center. It was not organized regularly, though the intention was to make it happen once a month. When I went there the first week of October, I realized the vastness of waste even on a tiny coastal area. An incident in January 2019, when a freighter lost 342 containers near the Wadden Sea, boosted the importance of beach cleanups as educational events. The seal center was one of the main organizers of the January beach cleanups, where I was also present on site to assist with the organization. For the scope of this article, I will draw on the notes of my first monthly cleanup in October 2018 only, but the analysis of how it matters is partly informed by the January cleanups that followed later.

During the different events, personal feelings and experiences were essential to inform my analysis. To work with this analytically, Rebecca Olive (2020) argues that shared lived experiences become a "tool to understanding the experiences of others" (Olive 2020: 123). She relates this to Elspeth Probyn's (1993) "thinking the social through myself." Reflecting on the researcher's own position in relation to those around her creates insights into social processes within context. Critical reflection is key: what we know is inherently situated (Haraway 1988). By stating explicitly how it is situated, we engage with the strengths and limitations of knowledge produced. At the seal center, I was a temporary insider as a female volunteer, being situated among volunteers and employees of the seal center. While I got acquainted with most of the employees and volunteers on an individual basis, the visiting public was diverse and dispersed and interactions too limited to get an intimate knowledge of their experiences. This means that my analysis will not focus on the experience of visitors in particular but is written from a shared experience between seal center staff and volunteers. Moreover, my fieldnotes are written from a human perspective, rather than that of a seal. Still, the analysis is certainly informed by both visitors and seals, as my experiences developed in relation to them. As such, research through experience is relational as it is done with others (Evers 2006). Even though the notes are written by one, they are informed by many. As researchers, we can be both the objects and subjects of research, learning and theorizing from our own experiences to unsettle current understandings (Mann et al. 2011). Through carefully reflecting on my experiences and personal observations that are informed by more-than-human actors during educational events, I will link this in-depth knowledge to natureculture processes.

Additionally, I started blogging for the seal center to check if my written experiences resonated with others. Those blogs were posted on the seal center's website and Facebook. Blogging gives the possibility to share personal reflections with a wide range of people interested (Olive 2012). While reactions on the posts themselves were scarce, during my stay several staff members mentioned my blogs and related to them, often in positive ways. This showed me how my experiences were shared, at least within the context of the seal center.

\section{Pristine nature}

The "boat release" is one of the major events the seal center organizes. In total forty people can join the boat, including participants, skipper, helmsman, volunteers, and employees of the seal center. Participants have to pay for a ticket to subscribe to a boat release. The trip is planned for participants to experience the outdoor environment in the midst of the most characteristic moment of the Wadden Sea: low tide.

Sunday, $19^{\text {th }}$ of November 2018

We meander between the sandbanks, which are starting to show as the ebb flow progresses. It is a cold but sunny November afternoon. Inside the heater is on, providing everyone with comfortable warmth, but still participants go outside to enjoy a wider view of the sea. [...] The skipper anchors the boat at a sandbank where many seals are lying around. Disturbed, they hop into the water as we are closing in.

All the participants, including the seals who are to be released, get from the boat to the sandbank. Although I was here with another group yesterday, our footprints have already been erased by the currents and waves of the sea, making it look like an empty, desolated space. The employee of the seal center calls everyone to stand in one line from the wooden crates which housed the seals during the journey to the waterline to start the release. In that way, pictures will not capture any people but only 'nature'. When the lids of the 
Fig. 1 Releasing seals on the sandbank Picture by author

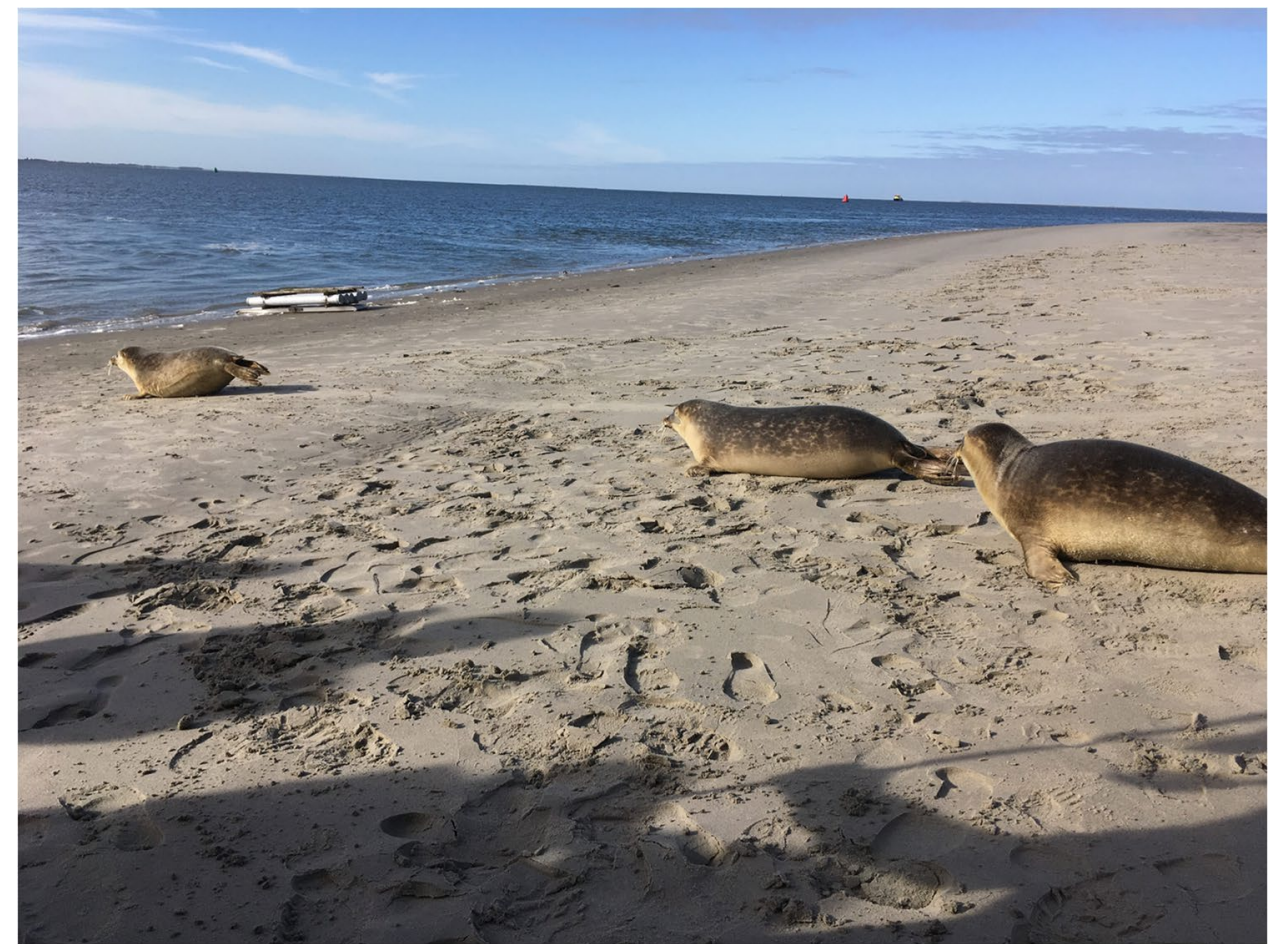

crates are lifted, the first seal is out of the box quickly. The other seals follow more slowly, until they reach the water. Further away the seals who were lying on the sandbank before are swimming. Some participants stay to watch the seals leaving, which are popping up with their heads now and then. Others start wandering around on the sandbank, until it is time to leave.

During this trip and release, the Wadden Sea environment emerged as two different moments of togetherness in which 'nature' and 'culture' distinctions were reproduced. First, on the way to the sandbank, the sea and sandbanks during the low tide call on people to come outside and enjoy the spectacular views during the trip. Almost always there are seals on the particular sandbank where the skipper anchors the boat because of its strategical steepness. Just before the boat anchors, the sand on the sandbank seems untouched. The space is seemingly empty of humans: the sea erased the footsteps of the day before, there are seals lying around and views do not explicitly feature humans. The boat trip becomes a practice in which the distinction between nature and culture is emphasized. Traveling through the Wadden Area by boat during the ebb flow was and is still impressive for me. It makes me feel small, a visitor in a rough, dynamic landscape. A feeling that is shared more widely (Sijtsma et al. 2012). Humans are witnesses, enjoyers of the landscape and have no specific responsibility in forming this landscape during this practice.
Second, the togetherness shifts when the boat anchors and people get onto the sandbank. The sandbank transforms into an in-between space where the whole boat crew invades and disturbs the otherwise apparently-devoid-of-human space. Seals that were lying on the sandbank before, flee disturbed into the water, erasing their former non-human presence. Footsteps are more and more imprinted on the sand as participants, volunteers, and employees walk around, carrying the crates with rehabilitated seals onto the sand. When the seals are released, they transit from the human controlled rehabilitation environment to the Wadden Sea Area that, from the former impression, is otherwise devoid of human presence. Reminding of the boundary between nature and culture that still rules, an erasure of humans happens when pictures are made of the release in which no humans are part of the image. On the pictures, a crowd of forty people is behind the camera-except for their shadows-and the beautiful sandbank, sea, and seals are within the frame (Fig. 1). It is the practice of the release that relates humans as temporary actors to the seals and the Wadden Sea. For a short time, in an in-between space, there is the presence of humans that should not be there that should be literally out of the frame.

The space of transition comes to an end as the seals gradually get out of direct human influence and visibility. They dive under, are invisible for a while, and come up. They join the group of other seals that were already part of the Wadden Sea, those that were lying on the sandbanks. With the transition of the seals, participants slowly retreated to 
the boat, enjoying their short time at the in-between space that is the sandbank while it lasted. The release is for many participants and volunteers a unique experience. Visitors pay for the tickets and volunteers are generally allowed to join only one time, increasing the feeling that this is a space for humans for only a short, limited timeframe.

While the togetherness during the different stages of the release is dynamic, the dichotomy between nature and culture is reproduced continuously through the event. Even when participants become part of the landscape and change it by releasing seals to the sea or imprinting their footsteps, it is only temporary. Paradoxically, through the multispecies interaction between sea, seals, and humans, a nature/culture boundary emerges. It is through their position as visitors in this togetherness that a purified if not pristine nature can be experienced. But, to follow Radhika Govindrajan (2018: 154): what does it $d o$ ? How does it matter? The practices that lead to a purification of natureculture possibly help produce a lack of responsibility. Participants of the event come to stand outside of the hard work of care based on trial and error that creating a "working togetherness" entails (Abrahamsson and Bertoni 2014). As visitors, participants come to stand outside of a direct responsibility towards the seals, sandbanks, and the sea. Responseability, as Haraway (2008: 71) nicely unravels the word's implications, is the ability to respond in (multispecies) interaction: " $[R]$ esponsibility is a relationship crafted in intra-action through which entities, subjects and objects, come into being." It is this intra-action that disappears with the rehabilitated seals into a too broad Wadden Sea area that is enacted through the trip and release as a site for human spectatorship, rather than human participation. The skipper and employees of the center recognize this gap and actively confront the participants with stories about climate change and pollution. The combination of these practices creates openings for spontaneous uncareful behavior, demonstrated by a woman who carelessly discarded her cigarette butt onto the sandbank. While for some the amazement and stories might incite feelings of protection and care, for others a "pristine" self-perpetuating nature might weaken feelings of responsibility.

\section{Arranged naturecultures}

The visitor center exhibition informs visitors about the Wadden Sea through a carefully arranged partial presence of what resides in it. It aims to incite care, not only for seals but for the ecosystem of the Wadden Sea environment as a whole. Singling out seals from the population in the Wadden Sea plays an important role in this educational strategy. Individual seals become "ambassadors" of the Wadden Sea and as fellow "members" of their species, as a metonymy, they attract visitors with the goal to tell and show people about the ambassador's species and the environment they live in-similar to the educational strategy of zoos (Braverman 2012: 8).

Seals at the visitor center bring in the Wadden Sea in particular ways. Seals are presented as bio-indicators throughout the visitor center, embodying pollution in the sea and marking the way in which it affects seals. Seals are at the top of the food chain in the Wadden Sea. They eat fish which also carry sea microbes, so microbes and pollutants present in the sea concentrate in seal bodies. The seal center exhibits petri-dishes filled with the filtered content of seal stomachs in order to mediate the polluted environment that seals live in. These petri-dishes are filled with blue and orange colored plastic threads. Plastic, a human-made product, resides in the body of the seal, which signifies that plastic is everywhere in the Wadden Sea and part of all the organisms living there. The seal center uses visual media to highlight other items that seals have brought from their regular habitat into the rehabilitation center. Seals entangled in fishing nets, rubber, and plastic are displayed on pictures in the exhibition. Visitors can open a drawer below the pictures of entangled seals and find the pieces of waste which have been removed from the seal's flippers or necks by seal center veterinarians. Fishing nets hanging from the walls and ceiling of the exhibition area serve to remind visitors of this reality. On top of that, multiple short movies of veterinarians removing metal such as fishing hooks out of a seal's body confront the visitors with vehement close-ups and $\mathrm{x}$-ray images. The seals that show up on the pictures or videos have all been rehabilitated in the seal center. While the seals have once been entangled with waste, the seal center shows to the visitors on screen how they consider it their task to disentangle seals from the hurtful consequences of societal pollution-an act of purification in Latourian terms.

The exhibition evades the matter of accountability. There is no mentioning of concrete behavior causing plastic to be there. As the humans represented become as general as the seals and the objects, visitors themselves are confronted with a problem without being directly part of it. As an exception, the seal center is an active participant in the relations of a caring "togetherness." The seal center removes inorganic waste from seals and releases them again. In these relations, the seal center is an actively caring participant taking responsibility, in close relation with anonymous human polluters and seal victims. Meanwhile the exhibition leaves visitors to be on the sideline of the togetherness, unconnected, and passive as non-acting spectators of harmful behavior.

In contrast, the visitor center focuses on the behavior of seals in rehabilitation to instruct visitors how to behave when they would encounter harbor or grey seals at the Wadden Sea. During a tour behind the scenes, a seal moved its front flipper up and down with a fast pace against the fence, after which the following conversation unfolded: 
Visitor: "Look he [the seal] is waving!"

Tourguide: "What does it mean when a seal moves its front flipper like that? I hear someone say waving, and I hear that a lot, but that is not what it means. [...] It is a sign of irritation. At this moment, the seal might just be irritated by the fence, but they can also do this to other seals or humans if they think they get too close. It is their way of saying something like: Hey, you are too close, can you keep your distance from me please?"

From the interaction between seals, visitors, and tour guide an educational moment ensued (Brown 2019). The tour guide took this as an opportunity to teach the visitors about seal behavior. In this way, visitors will be able to respond by reading the seal's signals. It creates the potential for a multispecies interaction that is focused on disengagement (Candea 2010). Therefore, visitors will be able to pick up on the sign not only in the seal rehabilitation center, but also at the Wadden Sea area. The matter of maintaining distance was also shared at other instances. For example, a guide integrated it into his presentation: "Sometimes people see a seal and call us to ask: 'What should I do if I see a seal?' Well, if you do not have experience with handling seals, you should do nothing. You should keep at a distance."

The matter of keeping distance is an interesting one. In the shared space of the Wadden Sea, humans and seals need to engage with one another in responsible ways. As humans are still conceived to be a disturbing factor for seals, they better maintain a distance from each other. By emphasizing to visitors that a lack of interaction is a good thing, especially when the seals go back to sea, the visitor center guides teach their public to be aware of and respect the distance that seals not only should, but also want to retain from humans in the Wadden Sea. Maintaining distance becomes a matter of care that respects the preferences of the seals.

The togetherness that emerges during the exhibition is dynamic and depends on the level of interaction between visitors, seals, and guides. Both forms of togetherness seem to enact a hybrid natureculture. The objects and seals at the seal center become partially connected to the Wadden Sea (Strathern 1991). They relate the visitor to a much-polluted Wadden Sea area through connection with seals living in that habitat. In this case, the togetherness, in contrast to the one Abrahamsson and Bertoni (2014) describe, exceeds what is directly present, as it includes what it partially connects to. The waste on display is not just a former part of a polluted Wadden Sea; it also evidences human presence and influence in the Wadden Sea area via inorganic waste. With the arranged objects, relations are forged between plastics that have arrived with seals at the seal center and that have been exhibited; "plastic pollution" at the Wadden Sea; unspecified "humans" who cause plastic to be there; specific seals who have ended up in rehabilitation; "seals" living in the Wadden Sea; and the employees of the seal center who relieve seals from hurtful circumstances. The presence of human influences in the Wadden Sea confronts visitors with inherent natureculture relations. However, the exhibition sidelines visitors as active participants and shows an act of purification: removing pollution from the seals is enacted by employees of the seal center only. The position of visitors at the sideline of the togetherness makes them passive like during the boat release, by which the call to create a caring attitude towards the local environment, an explicit goal set by the seal center, exactly loses considerable ground in the visitor center.

During interaction with seals, visitors, and guides at the visitor center, the togetherness includes not only those directly present but also "seals" at the Wadden Sea more generally that are partially connected. During some of the tours, visitors are reminded of their own position in the togetherness, and the ways they can respond and care in multispecies communication. Different from the arranged objects in the exhibition, visitors become and are acknowledged as active participants in the multispecies area of the Wadden Sea. Both forms of togetherness reproduce natureculture relations but at the same time differ by positioning visitors differently. Even within the visitor center, a togetherness is instable, dynamic, and depends on the relations forged in a certain moment, as relations come and go connecting even those that are absent depending on the situation. As such, the positions different humans take in the togetherness become fuzzy, because any boundary in natureculture relations is constantly moving, dynamic, and at times displaced.

\section{Disturbed natures}

The seal center organizes beach cleanups once a month. During one cleanup, I was struck by the large amount of plastic that was everywhere on the dyke of the harbor we were cleaning:

Sunday, $7^{\text {th }}$ of October 2018

With around thirty people, including subscribed participants, volunteers and employees of the seal center, we scatter over the dyke, searching for rubbish. Every one of us got a bucket to fill with pollutants. Squatting down by the seaweed, I see a small bright orange colored thread sticking out. I pull it out and dump it in the bucket, happy with this small contribution I made. Without moving an inch, I see another thread, and another. It leads me to rummage through the seaweed, where I continue to be for two hours straight, picking and plucking small bright colored threads, chemical soap remains, balloons, lids of plastic bottles, Styro- 
foam and other plastic remains of packaging material. Meanwhile, an unpleasant scent of warmed up, moist seaweed ascents, and tiny flies fly around disturbed with the movement. As I slowly move on plucking in another meter of seaweed, I notice other people going through the seaweed I had already 'cleaned'. They continue to take out stuff I had not noticed, even though I already got so much out of it. I feel devastated.

I wrote about my experience in a blog for the seal center, which was referred to multiple times by one of the guides when he would talk about the dire state of the Wadden Sea with visitors in the visitor center. My experience was shared, at least with him.

My reaction was closely linked to my care work in the seal center, where I had come to know seals as individuals. There, I was faced with the differences in character between seals. For example, when I cared for one seal, he threatened to attack me and I had to flee, calling in the help of another volunteer. Only a moment later, I was caring for a different seal who was playful and minding her own business. Even within a few days, the same seal could respond differently to me depending on its or my mood. As an experienced caretaker told me:

Some animals, yeah, some people will have an okay time with [...], and some people maybe not, your atmospheres together are off. I also have experienced that. An animal just doesn't like me, or I just look at him and it's like 'oh he is pissed with me, great'. I think you can say it's like, how humans are together. Not every person has a feeling towards each other. I think it is the same with them as well. So, it matches, or it doesn't match.

Starting volunteers like myself also learn to recognize the individual differences in character between seals. Each seal has its own personality, as diverse as the people who work with them.

During the cleanup I became more aware that the seals I had come to not only care for, but also about, were faced with these large amounts of pollution. It got into their stomachs, as it did into those of birds and fish. By cleaning the beach, I was able to respond in multispecies interaction by taking care that at least those pieces of rubbish would not hurt others. Contrary to the centeredness of seals in the togetherness of the exhibition, seals are absent during the beach cleanup. They are in my thoughts, but not visibly or bodily near. Reflecting on this experience, I recognize the influence of "slow pedagogy of place," the idea that it takes recurrent experiences and activities, doing, to become familiar with place or non-human others (Payne and Wattchow 2009a, b). Personification and naming are an important part of this too (Hill and Brown 2014: 225). By naming landscapes, people connect to the place instead of being "mere" unconnected visitors. It may explain why I so strongly connected with the landscape and seals during the act of the cleanup. I had worked at the seal center when the first clean-up took place, with embodied close experiences with seals. Those who explicitly shared my experience were particularly those working at the seal center as well. While the feelings caused by cleaning might not be as strong when this is a stand-alone experience, in any case a cleaner is an active, caring participant in the context of this togetherness.

To understand the "togetherness" that emerges in the practices of a beach cleanup, it is helpful to turn to Mary Douglas' Purity and Danger (1966), as she talks about dirt and pollution. Dirt, she says, is "matter out of place," depending on its context (1966: 35). So, while plastic is fine within the house, it becomes dirt when found in the sea and on the beach. Matter out of place disturbs classifications that people live by (ibid.: 36). The classifications disturbed by inorganic waste in the sea deeply unsettle any boundaries between "nature" and "culture." These pollutants are generally agreed to be harmful to the sea and its inhabitants (Worm et al. 2017). Participants of beach cleanups forcefully reject pollutants as part of the Wadden Sea environment. It is this strong rejection of inorganic, harmful characteristic of plastic pollutants that made us do at that moment what we did. Doing away with the anomaly was a way to react on its existence. By removing only few of the pollutants, we exerted a bit of physical control on the anomaly to keep the "nature/culture: boundary intact (Douglas 1966: 39). It is a quite literal act of "purifying" nature.

Douglas' approach theorizes how a system of meaning is kept stable, while allowing long-term change. However, the process of the beach cleanup is messier. People are working with the hope of a different "nature," but the nature that is meanwhile enacted through waste, cleaners, and perhaps distant seals and fish is one to which cleaners feel connected and responsible. A more dynamic, practice approach allows for a messier interpretation of natureculture relations that are simultaneously enacted and resisted (De Wolff 2017: 24). Through the act of cleaning, humans become participants essential to the enactment of nature. (Plastic) pollution creates an unsafe space for seals and other organisms living in the sea, and apparently calls on certain people to participate with a caring attitude towards the local environment. Cleaning the sea is a deeply place-responsive act. It can be a heavy bodily effort, if it is through smell or stiffening long squats at the seaweed. In that way, people become part of the togetherness through natureculture relations. From this perspective, the ideal of actually cleaning and thus "purifying" the environment is one aspect of the togetherness in which nature/culture boundaries are kept in place. With monthly cleanups it is obvious that the washing ashore of pollution is constant, and the endlessness of pollutants in the 
environment is experienced when cleaning: it is never actually "clean" of pollutants. By organizing a monthly beach cleanup as an educational event, the seal center engages and lives with pollution (Evers 2019) and uses it for educational purposes to reveal the local present. The educational message can be rightfully criticized for placing the responsibility on consumers rather than producers, and problematically framing a focus on plastics that can be separated from the lived environment rather than problematize microplastics that are unremovable and intimately entangled with life (resp. Jorgensen et al. 2021: 156; Liboiron 2016). Still, the intense and embodied experience that cleaning provides, creates connections not only with the local landscape, but also with inorganic waste, and potentially the organisms living in the sea. Participants at the event simultaneously relate to "nature" as caretakers while imagining "nature" as something that might exclude them once purified.

\section{Conclusion: creating a care attitude for "the" Wadden Sea}

The seal center wants to encourage a caring attitude by inspiring people to engage responsibly with the Wadden Sea as ecosystem. However, what 'the Wadden Sea' becomes during educative activities proves to be more complex and dynamic than might seem at face value, even within one nature conservation organization. As Emily Yates-Doerr and Annemarie Mol (2012: 50) show, when looked upon closely, 'the west' enacts multiple 'natures'. Using the concept of 'togetherness', I have explored this multiplicity with extra attention to what positions 'humans' take with regard to different kinds of togetherness. A practice approach allowed for a dynamic analysis of the relations enacted during an educational event. So, when the boat release took place, the togetherness included human participants, but only as temporary visitors. Participants get distanced from the rest of the togetherness that is closer connected: seals, the sea, and the sandbank. Visitors get distanced not just because 'nature' becomes enacted as non-human by the format of the event, but also because the landscape erases former human presence. Additionally, seals come to embody the transgression of a boundary between a space controlled by the rehabilitation center to a space outside this direct control when they are released from rehabilitation and join other seals. A nature/culture boundary and the idea of a pristine nature is here reproduced through purifying the environment from human presence. Still, through the practice approach, nuance is maintained, because "humans" are still part of natureculture relations in a role of legitimate visitors, even if that reproduces boundary making.
In the exhibition space of the seal center, in contrast, the natureculture relations are messier. The exhibition shows how the Wadden Sea inhabits inorganic waste, seals, and seal caretakers to disentangle seals from waste. The presence of inorganic waste points to a general absent presence of human influence on the Wadden Sea that is extremely pervasive. These "humans" that are at its source are not personified and are displayed strongly connected though poorly traceable. They are part of the "arranged nature" at the exhibition, highlighting an aspect of natureculture relations. Some humans, such as the anonymous polluters and heroic seal center staff, become part of the "arranged nature" at the exhibition, while visitors do not seem to count when displaying what or who is part of the Wadden Sea. During presentations and tours in contrast, the presence of visitors at the Wadden Sea is acknowledged, and they are taught ways to behave responsibly in multispecies encounters. Moments like these show how spontaneous behavior of seals, visitors and guides bring in the potential to emphasize natureculture relations, even when visitors are generally sidelined as active participants.

When tracing connections, I have made use of the concept of "togetherness" and focused on what is most closely connected. That did not mean a physical presence though. By centering my method of participant observation, experience and feelings guided what counted as present in the togetherness that ensued from the event. In that way, absent presences could be included in the relations of a togetherness, even when a material or physical connection missed. So, in the "arranged nature" of the exhibition anonymous and general humans, seals and waste were present in the togetherness. Importantly also, the togetherness that emerged during disturbed naturecultures of the beach cleanup could include seals I acquainted as a volunteer at the seal center. The beach cleanup (but not only the beach cleanup) was further much informed by embodied experience. This has been proven to be important in making connections with wildlife or landscape during outdoor education events (Hill and Brown 2014). Moreover, experience, although personal and human centered, is informed by others, including nonhuman organisms, objects, or landscapes. As such, it was possible to see how in some instances participants had a very distant relation to the rest of the togetherness, while in other instances such as the beach cleanup, cleaners were closely connected as careful participants in a polluted reality they were not pleased with. At the same time, the dynamic potential of the practice approach made it possible to see how simultaneously a nature/culture boundary was produced as cleaning was itself an act of purifying nature from inorganic pollution.

With this article, I have shown the dynamics of natureculture relations at the Wadden Sea, as well as the position certain humans take within those relations. This analysis 
challenges and affirms on some points the current literature on the Wadden Sea that focuses on interview data or written documents that primarily find a clear nature/culture boundary in this area, particularly in the Netherlands at nature conservation organizations (Walsh 2020; De Koning and Steins 2019; Egberts 2019). Because the focus was on practices in which there was room for spontaneity, purification rhetoric that seemed to reproduce these boundaries proved to be much messier in practice. Depending on the activity, "nature" might be enacted as pure or impure, there might be a role or no role for unskilled participants, and people might be pressed to develop an attitude of care or merely witness, or anything in between. Inspiring a care attitude through experiences is not that simple. Practice proves to be messier than that, but through its mess, it shows that openings for human participation in a "natural environment" are actually quite abundant.

Acknowledgements I am grateful to everyone at the seal center who was so open and welcoming to me and my research, without them this research would not have been possible. My thanks go out to my Research Master thesis supervisor, Oskar Verkaaik; to the organizers of this special edition with special thanks to Martin Döring; and to the reviewers of this article whose comments helped to improve this article considerably. CLUE+ has supported the open access publication of this article.

\section{Declarations}

Conflict of interest The author states that there is no conflict of interest.

Open Access This article is licensed under a Creative Commons Attribution 4.0 International License, which permits use, sharing, adaptation, distribution and reproduction in any medium or format, as long as you give appropriate credit to the original author(s) and the source, provide a link to the Creative Commons licence, and indicate if changes were made. The images or other third party material in this article are included in the article's Creative Commons licence, unless indicated otherwise in a credit line to the material. If material is not included in the article's Creative Commons licence and your intended use is not permitted by statutory regulation or exceeds the permitted use, you will need to obtain permission directly from the copyright holder. To view a copy of this licence, visit http://creativecommons.org/licenses/by/4.0/.

\section{References}

Abrahamsson, Sebastiaan, and Filippo Bertoni. 2014. Compost politics: Experimenting with togetherness in vermicomposting. Environmental Humanities 4: 125-148.

Barad, Karen. 2007. Meeting the universe halfway: Quantum physics and the entanglement of matter and meaning. Durham: Duke University Press.

Bazelmans, Jos, Dirk Meier, Annet Nieuwhof, Theo Spek, and Peter Vos. 2012. Understanding the cultural historical value of the Wadden Sea region. The co-evolution of environment and society in the Wadden Sea area in the Holocene up until early modern times (11,700 BC-1800 AD): An outline. Ocean and Coastal Management 68: 114-126.
Bonnett, Michael. 2013. Sustainable development, environmental education, and the significance of being in place. Curriculum Journal 24 (2): $250-271$.

Braverman, Irus. 2012. Zooland. The institution of captivity. Stanford: Stanford University Press.

Brown, Mike. 2019. Sailing, health and wellbeing: A thalassographic perspective. In Blue Space, Health and Wellbeing: Hydrophilia unbounded, ed. Ronan Foley, Robin Kearns, Thomas Kistemann, and Ben Wheeler, 52-64. London: Routledge.

Candea, Matei. 2010. "I fell in love with Carlos the Meerkat". Engagement and detachment in human-animal relations. American Ethnologist 37 (2): 241-258.

Cronon, William. 1996. The trouble with wilderness: Or, getting back to the wrong nature. Environmental History 1 (1): 7-28.

Danby, Paula, Katherine Dashper, and Rebecca Finkel. 2019. Multispecies leisure: Human-animal interactions in leisure landscapes. Leisure Studies 38 (3): 291-302.

De Koning, Susan and Nathalie A. Steins. 2019. Percepties van een Rijke Waddenzee. Van dynamisch en productief tot soortenrijk en ongerept. Yerseke: Wageningen Marine Research. (Wageningen Marine Research report; C071/19).

De Wolff, Kim. 2017. Plastic naturecultures Multispecies ethnography and the dangers of separating living from nonliving bodies. Body and Society 23 (3): 23-47.

Deleuze, Gilles and Félix Guattari. 1987. A thousand plateaus. Capitalism and schizophrenia. Minneapolis: University of Minnesota Press.

Douglas, Mary. 1966. Purity and Danger: An analysis of concepts of pollution and taboo. London: Routledge.

Egberts, Linde. 2019. Moving beyond the hard boundary: Overcoming the nature-culture divide in the Dutch Wadden Sea area. Journal of Cultural Heritage Management and Sustainable Development 9 (1): 62-73.

Enermark, Jens. 2005. The Wadden Sea protection and management scheme-towards an integrated coastal management approach? Ocean and Coastal Management 48: 996-1015.

Evers, Clifton. 2006. How to surf. Journal of Sport and Social Issues 30 (3): 229-243.

Evers, Clifton. 2019. Polluted leisure. Leisure Sciences 41 (5): 423-440.

Govindrajan, Radhika. 2018. Animal intimacies. Interspecies relatedness in India's Central Himalayas. Chicago: The University of Chicago Press.

Haraway, Donna J. 1988. Situated knowledges. The science question in feminism and the privilege of partial perspective. Feminist Studies 14 (3): 575-599.

Haraway, Donna J. 2003. The companion species manifesto. Dogs, people, and significant otherness. Chicago: Prickly Paradigm Press.

Haraway, Donna J. 2008. When Species Meet. Minneapolis: Minneapolis University Press.

Helmreich, Stefan. 2009. Alien Ocean. Anthropological voyages in microbial seas. Berkeley: University of California Press.

Hill, Allen, and Mike Brown. 2014. Intersections between place, sustainability and transformative outdoor experiences. Journal of Adventure Education and Outdoor Learning 14 (3): 217-232.

Hörst, Doortje. 2019. Individual, population, environment. Balancing perspectives of care for seals and the Wadden Sea. Amsterdam: University of Amsterdam.

Jorgensen, Bethany, Marianne Krasny, and Juan Baztan. 2021. Volunteer beach cleanups. Civic environmental stewardship combating global plastic pollution. Sustainability Science 16: 153-167.

Kabat, Pavel, Jos Bazelmans, Jouke van Dijk, Peter M.J.. Herman, Tim van Oijen, Morten Pejrup, Karsten Reise, Hessel Speelman, and Wim J. Wolff. 2012. The Wadden Sea Region: Towards a science for sustainable development. Ocean and Coastal Management 68: 4-17. 
Krauss, Werner. 2005. The natural and cultural landscape heritage of Northern Friesland. International Journal of Heritage Studies 11 (1): 39-52.

Kirksey, S. Eben., and Stefan Helmreich. 2010. The emergence of multispecies ethnography. Cultural Anthropology 25 (4): 545-576.

Latour, Bruno. 1993. We have never been modern. Cambridge: Harvard University Press.

Law, John. 2004. And if the global were small and noncoherent? Method, complexity, and the baroque. Environment and Planning $d$ : Society and Space 22: 13-26.

Law, John and Annemarie Mol. 2008. The actor-enacted: Cumbrian sheep in 2001. In: Material agency. Towards a non-anthropocentric approach, eds. Carl Knappett and Lambros Malafouris, 57-77. New York: Springer.

Liboiron, Max. 2016. Redefining pollution and action The matter of plastics. Journal of Material Culture 21 (1): 87-110.

Mann A, Annemarie Mol, Priya Satalkar, Amalinda Savirani, Nasima Selim, Maline Sur and Emily Yates-Doerr. 2011. Mixing methods, tasting fingers Notes on an ethnographic experiment. $H A U$ : Journal of Ethnographic Theory 1(1): 221-243.

Mannion, Greg, Ashley Fenwick, and Jonathan Lynch. 2013. Placeresponsive pedagogies: Learning from teachers' experiences of excursions in nature. Environmental Education Research 19 (6): 792-809.

Ministerie van Infrastructuur en Waterstaat. 2020. Ontwerp-agenda voor het Waddengebied 2050. Koersen naar een veilig, vitaal en veerkrachtig Waddengebied in 2050. http://www.gebiedsagendawa dden2050.nl/. Accessed 24 September 2020.

Mitchell, Audra, Sarah Wright, Sandie Suchet-Pearson, Kate Lloyd, Laklak Burarrwanga, Ritjilili Ganambarr, Merrkiyawuy Ganambarr-Stubbs, Banbapuy Ganambarr, R. Djawundil Maymuru, and Maymuru. . 2020. Dukarr lakarama: Listening to Guwak, talking back to space colonization. Political Geography 81: 1-10.

Mol, Annemarie. 2002. The body multiple: Ontology in medical practice. Durham and London: Duke University Press.

Olive, Rebecca J. 2012. 'Making friends with the neighbours': Blogging as a research method. International Journal of Cultural Studies 16 (1): 71-84.

Olive, Rebecca J. 2020. Thinking the social through myself. Reflexivity in research practice. In Research methods in outdoor studies, eds. Barbara Humberstone and Heather Prince, 121-129. New York: Routledge.

Payne, Philip G., and Brian Wattchow. 2009a. Phenomenological deconstruction, slow pedagogy and the corporeal turn in wild environmental/outdoor education. Canadian Journal of Environmental Education 13: 15-32.

Payne, Philip G., and Brian Wattchow. 2009b. Phenomenological deconstruction, slow pedagogy, and the corporeal turn in wild environmental/outdoor education. Canadian Journal of Environmental Education 14: 15-32.

Parreñas, Juno Salazar. 2018. Decolonizing extinction. The work of care in orangutan rehabilitation. Durham: Duke University Press.

Pols, Jeanette. 2006. Washing the citizen: Washing, cleanliness and citizenship in mental health care. Culture, Medicine and Psychiatry 30: 77-104.
Potter, Emily, and Gay Hawkins. 2009. Naturecultures: Introduction. Australian Humanities Review 46: 37-40.

Probyn, Elspeth. 1993. Sexing the self. Gendered positions in Cultural Studies. London: Routledge.

PuigdelaBellacasa, Maria. 2010. Ethical doings in naturecultures. Ethics, Place and Environment 13 (2): 151-169.

Rösner, Hans. 2019. The Wadden Sea: A natural landscape outside the dikes. In Waddenland Outstanding: History, Landscape and Cultural Heritage of the Wadden Sea Region, ed. Linde Egberts and Meindert Schroor, 81-94. Amsterdam: Amsterdam University Press.

Shotwell, Alexis. 2016. Against purity. Living ethically in compromised times. Chicago: University of Minnesota Press.

Sijtsma, Frans J., Michiel N. Daams, Hans Farjon, and Arjen E. Buijs. 2012. Deep feelings around a shallow coast. A spatial analysis of tourism jobs and the attractivity of nature in the Dutch Wadden area. Ocean and Coastal Management 68: 138-148.

Stichting Zeehondencentrum Pieterburen. 2018. Samengevoegd Jaarverslag 2018. https://www.zeehondencentrum.nl/downloads/ jaarverslagen/jaarverslag-2018.pdf. Accessed 13 June 2021.

Strathern, Marilyn. 1991. Partial Connections. New York: Altamira Press.

Sundberg, Juanita. 2013. Decolonizing posthumanist geographies. Cultural Geographies 21 (1): 33-47.

Tronto, Joan Claire. 1993. Moral boundaries: A political argument for an ethic of care. New York: Routledge.

Tsing, Anna Lowenhaupt. 2015. The Mushroom at the end of the world. On the possibility of life in capitalist ruins. Princeton: Princeton University Press.

Van Dooren, Thom, Eben Kirksey, and Ursula Münster. 2016. Multispecies Studies Cultivating Arts of Attentiveness. Environmental Humanities 8 (1): 1-23.

Wadden Sea Forum. 2013. ICZM Strategy for the Wadden Sea Region. Wilhelmshaven: Wadden Sea Forum e.V.

Walsh, Cormac. 2018. Metageographies of coastal management: Negotiating spaces of nature and culture at the Wadden Sea. Area 50: $177-185$.

Walsh, Cormac. 2020. Landscape Imaginaries and the Protection of Dynamic Nature at the Wadden Sea. Rural Landscapes: Society, Environment, History 7 (1): 1-20.

Worm, Boris, Heike K. Lotze, Isabelle Jubinville, Chris Wilcox, and Jenna Jambeck. 2017. Plastic as a persistent marine pollutant. Annual Review of Environment and Resources 42: 1-26.

Yates-Doerr, Emily, and Annemarie Mol. 2012. Cuts of meat: Disentangling Western natures-cultures. Cambridge Anthropology 30 (2): 48-64.

Publisher's note Springer Nature remains neutral with regard to jurisdictional claims in published maps and institutional affiliations. 